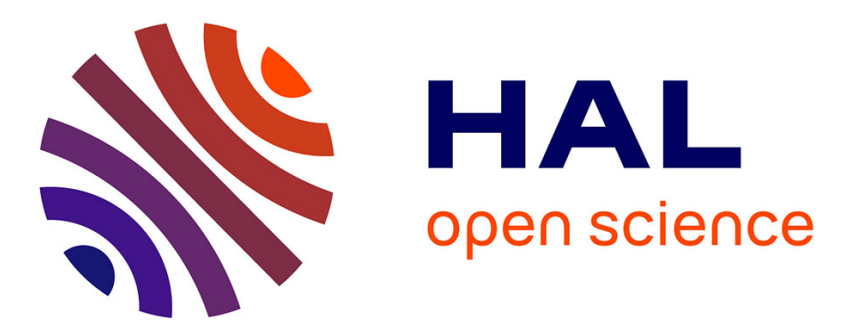

\title{
Deficit of cognitive inhibition in depressed elderly: a neurocognitive marker of suicidal risk
}

Stéphane Richard-Devantoy, Fabrice Jollant, Zied Kefi, G. Turecki, J. Olie, Cédric Annweiler, Olivier Beauchet, Didier Le Gall

\section{To cite this version:}

Stéphane Richard-Devantoy, Fabrice Jollant, Zied Kefi, G. Turecki, J. Olie, et al.. Deficit of cognitive inhibition in depressed elderly: a neurocognitive marker of suicidal risk. Journal of Affective Disorders, 2012, 140 (2), pp.193-9. 10.1016/j.jad.2012.03.006 . hal-03355846

\section{HAL Id: hal-03355846 \\ https://univ-angers.hal.science/hal-03355846}

Submitted on 27 Sep 2021

HAL is a multi-disciplinary open access archive for the deposit and dissemination of scientific research documents, whether they are published or not. The documents may come from teaching and research institutions in France or abroad, or from public or private research centers.
L'archive ouverte pluridisciplinaire HAL, est destinée au dépôt et à la diffusion de documents scientifiques de niveau recherche, publiés ou non, émanant des établissements d'enseignement et de recherche français ou étrangers, des laboratoires publics ou privés. 


\title{
Deficit of cognitive inhibition in depressed elderly: A neurocognitive marker of suicidal risk
}

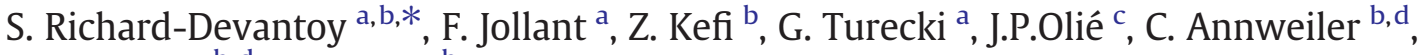 \\ O. Beauchet ${ }^{b, d}$, D. Le Gall ${ }^{b}$ \\ ${ }^{a}$ McGill University, Department of Psychiatry E' Douglas Mental Health University Institute McGill Group for Suicide Studies Montréal (Québec), Canada \\ b Laboratoire de Psychologie des Pays de la Loire, UPRES EA 4638, Angers University, Angers, France \\ c INSERM U796, Paris Descartes University and Sainte-Anne Hospital, France \\ d Department of Internal Medicine and Geriatrics, Angers University Hospital, Angers, France
}

\section{A R T I C L E I N F O}

\section{Article history:}

Received 10 January 2012

Received in revised form 9 February 2012

Accepted 3 March 2012

Available online 29 March 2012

\section{Keywords:}

Suicide attempts

Cognitive inhibition

Working memory

Depression

Elderly

\begin{abstract}
A B S T R A C T
Background: Cognitive deficits, in relation to ventral and dorsal prefrontal cortex dysfunctions, have been associated with a higher risk of suicidal acts in young adult patients. Although a public health concern, much less is known about the neurocognitive basis of suicidal behavior in elderly. Here, we aimed at assessing alterations in cognitive inhibition, a suspected major mechanism of the suicidal vulnerability, in suicidal depressed elderly.

Methods: We compared 20 currently depressed patients, aged 65 and older who recently attempted suicide to 20 elderly subjects with a current depression but no personal history of suicide attempt and 20 elderly controls. Using an extensive neuropsychological battery, we particularly examined different aspects of cognitive inhibition: access to relevant information (using the Reading with distraction task), suppression of no longer relevant information (Trail Making Test, Rule Shift Cards), and restraint of cognitive resources to relevant information (Stroop test, Hayling Sentence Completion test, Go/No-Go).

Results: After adjustment for age, intensity of depression, Mini-Mental State Examination score and speed of information processing, suicidal depressed elderly showed significant impairments in all 3 domains of cognitive inhibition in comparison to both control groups.

Limitations: Our results need replication in a larger sample size.

Conclusions: Our study suggests that the inability to inhibit neutral information access to working memory, restrain and delete irrelevant information may impair the patient's capacity to respond adequately to stressful situations subsequently leading to an increased risk of suicidal behavior during late-life depression. Interventions may be developed to specifically target cognitive impairment in the prevention of suicide in depressed elderly.
\end{abstract}

(c) 2012 Elsevier B.V. All rights reserved.

\section{Introduction}

Late-life suicide is a major public health issue (Diekstra and Gulbinat, 1993). Its prevalence is higher than in any other age

\footnotetext{
* Corresponding author at: McGill University, Department of Psychiatry \& Douglas Mental Health University Institute, McGill Group for Suicide Studies Montréal (Québec), Canada, Douglas Institute, FBC building, 3rd floor, 6875 boulevard Lasalle, Montréal (Qc), Canada H4H 1R3. Tel.: +1 514761 6131; fax: + 15148884466 .

E-mail address: richarddevantoy@orange.fr (S. Richard-Devantoy).
}

group (Conwell and Cailting, 2008), ranging from 30/100,000 to $120 / 100,000$ (Hawton and van Heeringen, 2009). Moreover, the ratio between suicide attempt and suicide completion in older adults has been estimated around 4:1 compared with 40:1 for younger people (Conwell and Cailting, 2008). Enhancing our understanding of the mechanisms of old-age suicidal acts is of major importance to improve prevention.

About 95\% of all suicides are associated with an axis I psychiatric disorder (Conwell and Cailting, 2008; Hawton and van Heeringen, 2009), most often a depressive disorder in later life (Alexopoulos et al., 1999; Szanto et al., 2001). 
Depression is known to involve cognitive dysfunctions (Hasselbalch et al., 2011), particularly in executive tasks (Elderkin-Thompson et al., 2007; Herrmann et al., 2007). Lower performances in episodic memory, verbal fluency, information processing, attention and executive functions have been reported among depressed elderly patients (Fossati, 2006; Herrmann et al., 2007). A current model of depression posits that the frontostriatal neural pathways are compromised during depressive episodes. Executive functions are heavily dependent on the frontostriatal circuitry and may serve as an indicator of the degree of frontostriatal compromise. Besides, age-related executive decline is highly prevalent and well identified in frontostriatal circuitry in older adults (Kramer et al., 1994; Turner and Spreng, 2012). Therefore, both depression and age may act to impair cognitive functions in elderly depressed patients.

However, a large number of studies now suggest specific cognitive alterations associated with a history of suicidal acts (Jollant et al., 2011) independently of comorbid depression. In younger adults, alterations in decision-making, problemsolving, attention or verbal fluency have been reported (Jollant et al., 2011). Unfortunately, little is known about cognitive performance in elderly suicide attempters (Dombrovski et al., 2008; King et al., 2000). King et al. (2000) showed a faster age-related decline in cognitive flexibility in the depressed suicide attempters relative to non-suicide attempter patients. Alterations in attention and memory have also been reported in elderly depressed suicide attempters (Dombrovski et al., 2008). In addition, Dombrovski et al. (2010) showed an association between impairment in a component of affective decision-making and attempted suicide in late-life depression. According to these authors, elderly depressed suicide attempters make overly present-focused decisions, ignoring past experiences (Dombrovski et al., 2011). However, decisionmaking necessitates different executive processes implicated in regulation and control during the treatment of complex and/or new and/or conflictual tasks (Seron et al., 1999).

Cognitive inhibition is a major component of executive functions. It is defined as the active suppression process that limits the stimuli not relevant for the on-going task (Miyake et al., 2000; Shallice and Burgess, 1991). According to Hasher and Zacks (Hasher et al., 1999), cognitive inhibition refers to an active process tempering unwanted (external or internal) stimuli that compete for processing resources in the context of a limited capacity system. Inhibitory mechanisms, therefore, serve to restrict access to relevant information, suppress information that is no longer relevant and restrain production of strong but potentially incorrect retrieval of information from working memory (Zacks et al., 1999) (Fig. 1).

During the suicidal crisis, it has been suggested that cognitive inhibition deficit could facilitate the committing of the suicidal act (Marzuk et al., 2005) because of the combined difficulty of excluding irrelevant information, of suppressing intrusive ideas - leading to an obsessional and ruminative mode of thinking - and of controlling the production of negative affects. Moreover, cognitive inhibition appears to be particularly sensitive to aging, making it a relevant topic of investigation in elderly patients (Marzuk et al., 2005). We, therefore, hypothesized that suicidal depressed elderly would have worse cognitive inhibition performance than nonsuicidal depressed elderly, and than healthy elderly.

\section{Methods}

\subsection{Population}

Three groups of participants aged 65 and older were recruited: 1) 20 inpatients with a current major depressive episode and a recent history of suicide attempt (suicidal depressed elderly); 2) 20 inpatients with a current major depressive episode but no personal lifetime history of suicide attempt (non-suicidal depressed elderly), and 3) 20 elderly subjects with no lifetime personal history of depression, suicide attempt or current psychopharmacological treatment (healthy controls). Patients and controls were all French native, with a Mini-Mental Scale Examination (Folstein et al., 1975 ) score $\geq 24$. Written informed consent was obtained from all participants.

Lifetime axis I psychiatric diagnoses were made according to the DSM-IV. Diagnostic assessment was done by experienced psychiatrists (S.R.D., and D.L.G.) with the French

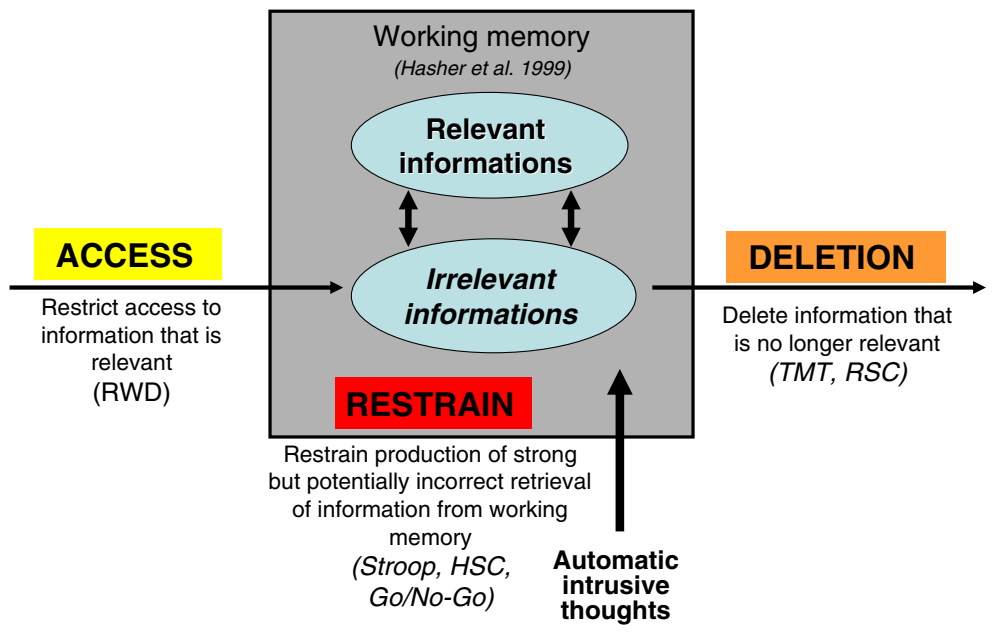

Fig. 1. Hasher and Zacks model of cognitive inhibition (21). This model was used in the current study to explore suicidal elderly. 
version of the Mini-International Neuropsychiatric Interview (Lecrubier et al., 1997), medical records, and any other information. Only depressive patients, without psychotic features, with a score of 18 or higher on the 17-item Hamilton Rating Scale of Depression (HRSD-17) were included. Suicidal depressed elderly had made a suicide attempt during the ten days before the admission in the unit. Non-inclusion criteria were bipolar disorder, schizophrenia, schizo-affective disorders, an electroconvulsive therapy in the previous six months and neurologic disorders including stroke, epilepsy, brain tumor or brain injury and sensory disorders that precluded cognitive testing.

Suicidal depressed elderly inpatients (median age $=77$ [65-89] years, $65 \%$ women) were matched to non-suicidal depressed elderly inpatients (median age $=75$ [65-89] years, $60 \%$ women) for age, education level and MMSE score. The suicide attempt methods used were: medication overdose (80\%), hanging (10\%), jumping from heights (5\%), and poisoning by toxic liquid substance (5\%). For 16 suicidal depressed elderly (80\%), it was the first suicide attempt. Suicide attempt history was verified by a psychiatrist, using the interview, medical records, and information from family or acquaintances. Participants with significant discrepancies between these sources were excluded. Forty percent of suicidal depressed elderly and $60 \%$ of non-suicidal depressed elderly had already suffered from a major depressive episode. None of the patients in recurrence of depression had been resistant to a prior antidepressant treatment.

At the time of assessment, all depressed elderly inpatients, suicidal and non-suicidal, were on an antidepressant treatment (SSRI), which began at admission to the unit. Neuropsychological tests were administered in one to two sessions over the course of 1-2 days and in the first three days after their admission in the unit, so before the treatment efficacy $($ HDRS $<18$ ) and in the first ten days after the suicide attempt.

During the same period, healthy controls without a psychiatric or neurological history or a suicidal history were recruited by advertisement in the community dwelling. They were free of psychotropic medication. All healthy controls had a 17item HDRS score below 7. Additional exclusion criteria for healthy controls were living in nursing home, a neurological disease, such as dementia, Parkinson disease, cerebellar disease, myelopathy, and peripheral neuropathy, and being unable to understand French or follow simple commands.

The study was conducted in accordance with the ethical standards set forth in the Helsinki Declaration (1983). The local ethics committee approved the project.

\subsection{Neuropsychological assessments}

The three domains of inhibition were evaluated on the basis of Hasher and Zacks' theoretical model (Hasher et al., 1999): 1) access with the Reading with distraction task (RWD) (Connelly et al., 1991), 2) suppression with the Trail Making Test (TMT) (Godefroy et al., 2008) and the Rule Shift Cards (RSC) (Godefroy et al., 2008), and 3) restraint with the Stroop Color test (Godefroy et al., 2008), the Hayling Sentence Completion test (HSC) (Burgess and Shallice, 1996) and the Go/No-Go (Godefroy et al., 2008). Other executive functions were also assessed with the Baddeley dual-task performance (Godefroy et al., 2008) and the verbal fluency test (Godefroy et al., 2008). All neuropsychological testing was conducted blind to clinical ratings and suicide history.

\subsection{Statistical analyses}

Regarding the small number of participants in each group, non-parametric tests were used. First, comparisons of quantitative values among groups were performed using or Kruskal-Wallis test (if more than three group comparisons) or Mann-Whitney $U$ test (if two-group comparisons). A Chi-square test was used to compare qualitative values. We performed a step by step regression analyses to specify the associations between suicide attempt (dependent variable) and neuropsychological tests scores (independent variable) with potential confounding factors (global cognitive functioning, age, intensity of depression and speed of information processing). A $\mathrm{p}<0.05$ was set a priori. Bonferroni corrections were applied for multiple comparisons. SPSS 17.0 (SPSS, Chicago, Illinois) was used.

\section{Results}

\subsection{Group characteristics}

The three groups (healthy controls, non-suicidal depressed elderly and suicidal depressed elderly) were statistically similar in terms of age, level of education, and MMSE score (Table 1). There was no difference between suicidal depressed and non-suicidal depressed elderly for clinical variables such as psychiatric history and Hamilton depression scores (Table 1 and 2). Of note, suicidal depressed elderly subjects had a high score on the suicide intent scale.

\subsection{Cognitive inhibition (Table 2)}

\subsubsection{Access function}

At the RWD task, suicidal depressed elderly were slower than healthy controls in reading all the 4 text forms. There were significant differences in the reading time of the original form $(U=68, p<.001)$ and those with semantic $(U=84$, $\mathrm{p}=.002)$, neutral $(\mathrm{U}=58, \mathrm{p}<.001)$ and non-words distractors $(\mathrm{U}=53.5, \mathrm{p}<.001)$. Suicidal depressed elderly read significantly more semantic $(U=110, p=.015)$ and neutral distracting words $(\mathrm{U}=101, \mathrm{p}=.007)$ than non-suicidal depressed elderly and more semantic $(U=19, p<.001)$, neutral distracting words $(\mathrm{U}=46.5, \mathrm{p}<.001)$ and non-words $(\mathrm{U}=110, \mathrm{p}=.003)$ than healthy controls.

\subsubsection{Suppression function}

Suicidal and non-suicidal depressed elderlies were slower than healthy controls to complete both parts of the TMT (Part $A(p<.001)$; Part $B(p<.001))$ and both groups made significantly more errors in Part $B(p<.001)$. Suicidal depressed elderly took as much time as non-suicidal depressed elderly to complete both parts of the TMT (Part A $(U=168.5$, $\mathrm{p}=.394)$; Part $\mathrm{B}(\mathrm{U}=150.5, \mathrm{p}=.180))$, but made significantly more errors in Part $B(U=98, p=.005)$.

Suicidal and non-suicidal depressed elderlies were slower than healthy controls to execute the part 2 of the RSC $(\mathrm{U}=112.5, \mathrm{p}=.02$ and $\mathrm{U}=123, \mathrm{p}=0.04)$ and both groups 
Table 1

Comparison of demographic and clinical characteristics of suicidal depressed elderly, non-suicidal depressed elderly and healthy comparison elderly.

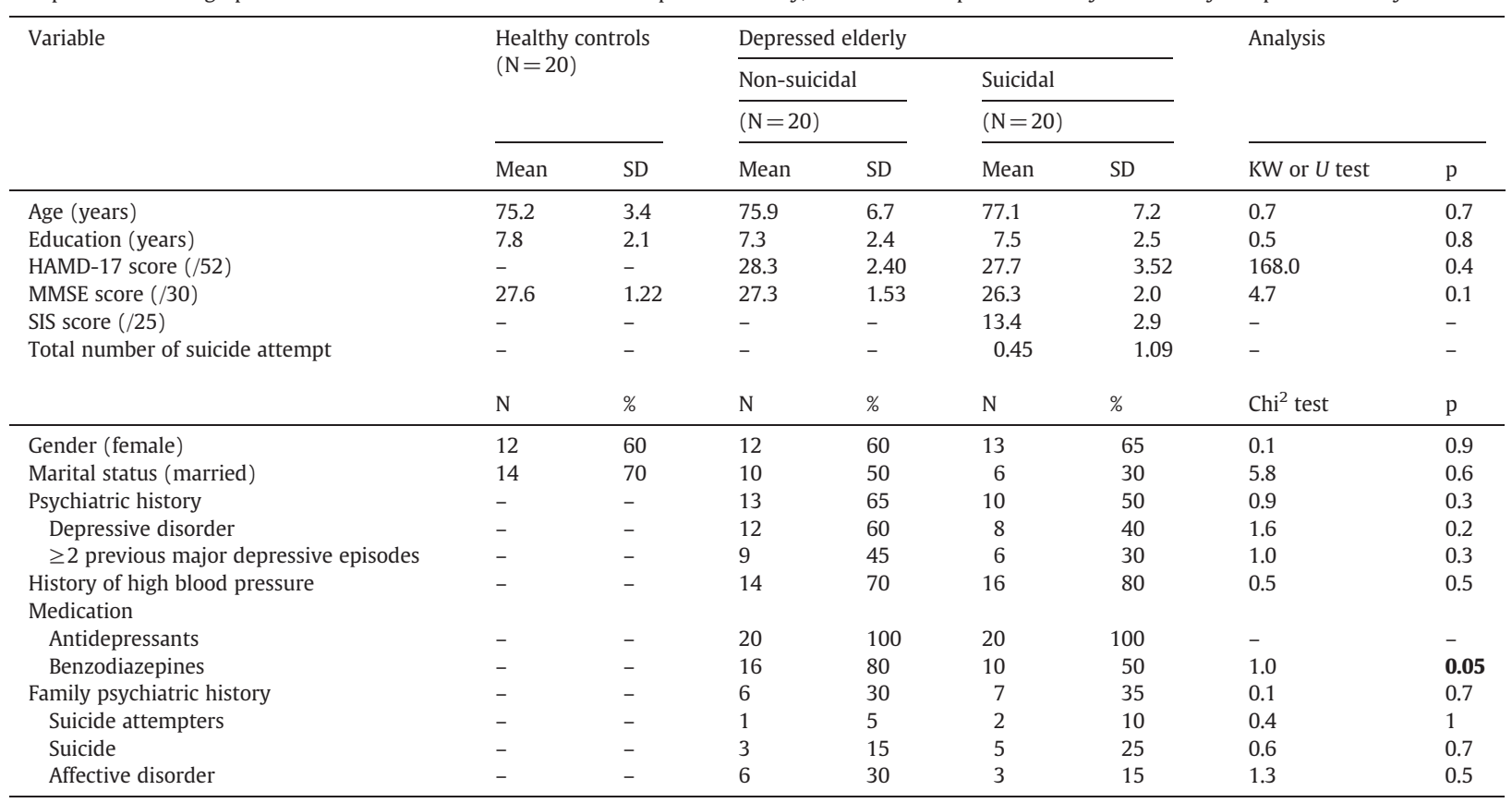

SD: Standard Deviation. HAMD: 17-item Hamilton Depression Scale; MMSE: Mini-Mental State Examination; SIS: Suicide Intent Scale of Beck. Mann-Whitney $U$ test. KW: Kruskal-Wallis test. Significant P-Value $(<0.05)$ indicated in bold.

made significantly more errors in part $2(\mathrm{U}=6.5, \mathrm{p}<.001$ and $\mathrm{U}=37.5, \mathrm{p}<.001)$. Suicidal depressed elderly made also significantly more errors in part 2 than non-suicidal depressed elderly $(\mathrm{U}=109, \mathrm{p}=.013)$.

\subsubsection{Restraint function}

Response time on the Stroop color test was significantly longer in suicidal depressed elderly compared to healthy controls $(U=53.5, p<.001)$, with no significant difference between suicidal and non-suicidal depressed groups. Suicidal depressed elderly made significantly more errors in the Stroop task than non-suicidal depressed elderly $(U=118.5$, $\mathrm{p}=.03)$ and healthy controls $(\mathrm{U}=78.5, \mathrm{p}<.001)$.

The performance in the second part of the HCS was worse in suicidal depressed patients than in non-suicidal depressed patients and healthy controls, with longer time $(U=113$, $\mathrm{p}=.02$ and $\mathrm{U}=2.0, \mathrm{p}<.001)$ and more errors $(U=83$, $\mathrm{p}=.002$ and $\mathrm{U}=0, \mathrm{p}<.001)$. Finally, suicidal depressed elderly showed worse performance on the Go/No-go task compared to non-suicidal depressed elderly $(U=103.5$, $\mathrm{p}=.006)$ and to healthy controls $(U=64, \mathrm{p}<.001)$.

After adjustment for age, intensity of depression, MMSE score and speed of information processing, suicidal depressed elderly read more distractors at RWD $(p=.01)$, made more errors in part B of TMT $(\mathrm{p}=.02)$ and in part 2 of RSC $(\mathrm{p}=.02)$, and made more errors in Stroop task $(\mathrm{p}=.01)$, in part $\mathrm{B}$ of Hayling test $(\mathrm{p}=.004)$ and in Go/No-Go task $(\mathrm{p}=.008)$ compared to both control groups.

We also found a positive correlation between the number of suicide attempts and Stroop interference score ( $r s=0.56$; $\mathrm{p}=.01$ ). No other correlation between suicidality (SIS, history of suicide attempts) and inhibition functions was significant.

\subsection{Other executive functions (Table 2)}

In the dual-task performance, suicidal depressed elderly did not significantly differ from non-suicidal depressed elderly. Healthy controls were better in simple $(U=59, p<.001$ and $\mathrm{U}=122, \mathrm{p}=.03)$ and dual task $(\mathrm{U}=50, \mathrm{p}<.001$ and $\mathrm{U}=76.5, \mathrm{p}=.001$ ) conditions than the other two groups.

There were no significant differences between suicidal and non-suicidal depressed groups in verbal fluency but healthy controls had a better verbal fluency than suicidal depressed elderly in semantic $(U=101, p=.007)$ or phonemic subtest $(\mathrm{U}=85.5, \mathrm{p}=.002)$. Healthy controls had also a better verbal fluency than depressed controls in phonemic subtest $(\mathrm{U}=122, \mathrm{p}=.03)$.

\section{Discussion}

In the present study, we showed that suicidal depressed elderly had poorer performance in the three functions of cognitive inhibition in comparison to non-suicidal depressed elderly and healthy controls. To date, no study has assessed all domains of cognitive inhibition in relation to suicidal behavior, and few studies have examined the association between cognitive dysfunctions and suicidal behavior in latelife depression (Dombrovski et al., 2008; King et al., 2000). This study, therefore, adds important findings to the growing literature on both cognitive alterations associated with suicidal behavior and the particular population of old-age depressed individuals.

We found all functions of cognitive inhibition (access, suppression and restraint) to be impaired in elderly depressed suicide attempters. To our knowledge, the access function of 
Table 2

Comparison of neuropsychological tests between the suicidal depressed elderly, non-suicidal depressed elderly and healthy comparison elderly.

\begin{tabular}{|c|c|c|c|c|c|c|c|c|c|}
\hline \multirow[t]{3}{*}{ Domain and test } & \multicolumn{6}{|c|}{ Depressed elderly } & \multicolumn{3}{|l|}{ Analysis } \\
\hline & \multicolumn{2}{|c|}{$\begin{array}{l}\text { Healthy } \\
\text { comparison } \\
\text { elderly }(N=20) \\
\end{array}$} & \multicolumn{2}{|c|}{$\begin{array}{l}\text { Non-suicidal } \\
(\mathrm{N}=20)\end{array}$} & \multicolumn{2}{|c|}{ Suicidal $(\mathrm{N}=20)$} & \multirow[t]{2}{*}{ KW test } & \multirow[t]{2}{*}{$\mathrm{p}$} & \multirow[t]{2}{*}{ Post-hoc } \\
\hline & Mean & SD & Mean & SD & Mean & SD & & & \\
\hline \multicolumn{10}{|l|}{ Access function } \\
\hline RWD time (sec) T1 & 31.4 & 4.2 & 37.8 & 10.1 & 42.5 & 12.7 & 12.0 & 0.002 & $C>S$ \\
\hline RWD time (sec) T2 & 54.6 & 4.1 & 65.6 & 25.5 & 75.7 & 25.5 & 12.0 & 0.003 & $\mathrm{C}>\mathrm{S}=\mathrm{NS}$ \\
\hline RWD time (sec) T3 & 42.1 & 3.8 & 54.7 & 19.2 & 61.9 & 17.5 & 18.1 & $<0.001$ & $\mathrm{C}>\mathrm{S}=\mathrm{NS}$ \\
\hline RWD time (sec) T4 & 35.2 & 5.1 & 46.4 & 16.4 & 56.56 & 21.4 & 18.3 & $<0.001$ & $\mathrm{C}>\mathrm{S}=\mathrm{NS}$ \\
\hline Semantic distractors $\mathrm{T} 2$ & 0.4 & 0.6 & 3.5 & 3.1 & 7.0 & 4.8 & 34.6 & $<0.001$ & $\mathrm{C}>\mathrm{NS}>\mathrm{S}$ \\
\hline Neutral distractors T3 & 0.2 & 0.4 & 0.9 & 1.7 & 3.8 & 4.4 & 22.3 & $<0.001$ & $\mathrm{C}>\mathrm{NS}>\mathrm{S}$ \\
\hline Non-words T4 & 0.1 & 0.3 & 0.2 & 0.6 & 1.4 & 2.4 & 9.8 & 0.007 & $\mathrm{C}>\mathrm{S}$ \\
\hline \multicolumn{10}{|l|}{ Suppression function } \\
\hline $\mathrm{TMT}_{\mathrm{A}}$ time $(\mathrm{sec})$ & 39.8 & 15.7 & 78.2 & 34.8 & 101.4 & 63.4 & 23.3 & $<0.001$ & $\mathrm{C}>\mathrm{S}=\mathrm{NS}$ \\
\hline $\mathrm{TMT}_{\mathrm{B}}$ time $(\mathrm{sec})$ & 88.8 & 38.3 & 213.8 & 91.9 & 263.3 & 140.8 & 26.5 & $<0.001$ & $\mathrm{C}>\mathrm{S}=\mathrm{NS}$ \\
\hline Perseverations $\mathrm{TMT}_{\mathrm{B}}$ & 0.1 & 0.3 & 2.0 & 2.64 & 5 & 4.1 & 33.7 & $<0.001$ & $\mathrm{C}>\mathrm{NS}>\mathrm{S}$ \\
\hline RSC first rule time (sec) & 30.0 & 4.0 & 33.3 & 7.74 & 38.9 & 20.2 & 0.8 & 0.68 & \\
\hline RSC second rule time (sec) & 39.8 & 2.9 & 49.7 & 14.2 & 56.6 & 24.6 & 6.9 & 0.03 & $\mathrm{C}>\mathrm{NS}=\mathrm{S}$ \\
\hline RSC second rule errors & 0.4 & 0.6 & 3.80 & 2.7 & 6.2 & 3.1 & 36.1 & $<0.001$ & $\mathrm{C}>\mathrm{NS}>\mathrm{S}$ \\
\hline \multicolumn{10}{|l|}{ Restraint function } \\
\hline Go/No-go score $(/ 3)$ & 2.8 & 0.4 & 2.3 & 0.7 & 1.4 & 1.1 & 19.0 & $<0.001$ & $\mathrm{C}>\mathrm{NS}>\mathrm{S}$ \\
\hline Hayling $_{\mathrm{A}}$ time (sec) & 16.5 & 1.3 & 18.4 & 4.1 & 25.4 & 16.5 & 5.9 & 0.05 & $\mathrm{C}>\mathrm{S}$ \\
\hline Hayling $_{\mathrm{B}}$ time $(\mathrm{sec})$ & 28.6 & 5.3 & 64.0 & 19.6 & 94.7 & 45.6 & 41.4 & $<0.001$ & $\mathrm{C}>\mathrm{NS}>\mathrm{S}$ \\
\hline Hayling $_{\mathrm{B}}$ penalities & 0.9 & 1.0 & 16.7 & 7.8 & 27.2 & 10.1 & 44.0 & $<0.001$ & $\mathrm{C}>\mathrm{NS}>\mathrm{S}$ \\
\hline Stroop interference score (sec) & 122.3 & 39.3 & 185.4 & 63.4 & 255.1 & 115.2 & 20.6 & $<0.001$ & $C>S$ \\
\hline Stroop errors & 0.5 & 1.2 & 1.5 & 2.0 & 7.8 & 13.9 & 14.2 & 0.001 & $\mathrm{C}>\mathrm{NS}>\mathrm{S}$ \\
\hline \multicolumn{10}{|l|}{ Other executive functions } \\
\hline \multicolumn{10}{|l|}{ Baddeley } \\
\hline Single task sequences & 156 & 39.1 & 123.9 & 38.4 & 100.2 & 36.4 & 15.0 & 0.001 & $\mathrm{C}>\mathrm{NS}=\mathrm{S}$ \\
\hline Double task sequences & 142.4 & 37.1 & 96.5 & 31.7 & 82.1 & 35.3 & 19.4 & $<0.001$ & $C>S$ \\
\hline \multicolumn{10}{|l|}{ Verbal fluency } \\
\hline Phonemic & 19.1 & 5.9 & 16.5 & 4.7 & 12.9 & 7.4 & 8.1 & 0.01 & $\mathrm{C}>\mathrm{NS}=\mathrm{S}$ \\
\hline Semantic & 27.4 & 6.5 & 23.1 & 5.2 & 19.6 & 6.8 & 11.1 & 0.004 & $C>S$ \\
\hline
\end{tabular}

SD: Standard deviation; sec: seconds. C: healthy comparison subjects; NS: non-suicidal depressed elderly; S: suicidal depressed elderly. RWD: Reading with distraction task; TMT $=$ Trail Making Test. KW: Kruskal-Wallis test.

cognitive inhibition has never been evaluated by any previous study in suicide attempters. Alterations in the suppression function has previously been reported with poorer performances in the TMT Part B time index in younger adults and old-age suicide attempters (King et al., 2000; Marzuk et al., 2005), and in the Wisconsin Card Sorting Test (errors index) in younger adults (Keilp et al., 2001; Marzuk et al., 2005). Finally, Keilp et al. (2001) previously reported impairment in the restraint function in younger patients with more uncorrected errors at the Stroop test in depressed suicide attempters relative to depressed non-suicidal individuals. In a second study by Keilp et al. (2008), this deficit in Stroop performances was found in all depressed groups, but significantly greater in those with a history of suicide attempt. Moreover, Malloy-Diniz et al. (2009) found a positive and significant correlation between the number of suicide attempts and the number of errors in the Stroop test in younger bipolar I patients. In contrast to our results, impairment in the motor component of cognitive inhibition evaluated by the Go/NoGo test was observed in younger euthymic suicide attempters (Raust et al., 2007). Divergences may be related to the various comorbidities and the lack of a patient control group in the latter study.
It has been proposed that the suicidal crisis may result from both deficient value-based processes, facilitating the automatic triggering of an acute emotional state, and deficient regulatory processes (Jollant et al., 2011). Cognitive inhibition is a key mechanism in the regulation of emotions, thoughts and acts (Joormann and Gotlib, 2008). The deficits in cognitive inhibition observed in suicide attempters may facilitate the development of the suicidal crisis through, simultaneously, a lack of regulation of the provoked emotional state and the induction of a ruminative and obsessive mode of thinking leading to suicidal ideas and ultimately to a suicidal act (Jollant et al., 2011). First, deficit in the inhibition of moodcongruent material could result in prolonged processing of negative, goal-irrelevant information thereby hindering recovery from negative mood and leading to sustained negative affect (Joormann and Gotlib, 2008; Joormann et al., 2007). In addition, recent research has also demonstrated that deficient inhibition of negative material is associated with heightened ruminations (Morrison and O'Connor, 2008). Moreover, Hasher and Zacks (Hasher et al., 1999) have proposed that the efficient functioning of working memory depends on inhibitory processes that both limit the access of information into working memory and update the contents of working memory by 
removing information that is no longer relevant. In the case of suicide attempters, impaired cognitive inhibition would no longer reduce the intrusion of suicidal ideation, parasitizing the functioning of working memory. Furthermore, deficit in cognitive inhibition may reduce the possibility to make adequate choices during decision-making, a function previously reported to be altered in suicide attempters (Jollant et al., 2005), through the inability to correctly utilize adequate information to guide choices (McGirr et al., 2012). Finally, deficit in some aspects of cognitive inhibition measured by the Stroop seems to facilitate the act itself as the positive correlation between Stroop interference and the number of suicidal acts suggests. More investigations are necessary to disentangle the specific contribution of each function of cognitive inhibition to the different steps of the suicidal crisis.

Deficits of cognitive inhibition in suicidal depressed elderly may be related to the dysfunction of the dorsolateral cortex, a region previously associated with suicidal behavior (Jollant et al., 2011). Previous studies have implicated an important role of the dorsolateral prefrontal cortex to the implementation of working memory and the ability to inhibit responses (Kane and Engle, 2002; McDowd et al., 1995) that are not adapted and the intrusion of negative affect in depression (van Heeringen et al., 2011). Only future neuroimaging studies in elderly suicide attempters could confirm our hypotheses and shed light on the neuroanatomical basis of inhibitory deficits in old-age suicide attempters. Moreover, previous results suggest that neurocognitive alterations in suicide attempters may be related to pathological aging (King et al., 2000). Suicide vulnerability in elderly may, therefore, partly result from a higher sensitivity to the aging of prefrontal brain regions making them more susceptible to cognitive impairment including cognitive inhibition deficit (Wang et al., 2011).

Prediction and prevention of suicidal behavior are currently weak. Findings from our study may shed light on potential neurocognitive markers that could be added to the clinical signs and symptoms (insufficient per se (Harriss and Hawton, 2005)) to improve prediction of suicidal acts, in high risk (e.g. depressed) patients. A second perspective will be to use findings from this study to develop new therapeutic strategies. Assessment of executive function could help to adapt the therapeutic strategies (McLennan and Mathias, 2010). For instance, it has also been shown that alterations of cognitive inhibition in depressed elderly patients were associated with poor antidepressant response (Alexopoulos et al., 2005, 2009; Butters et al., 2004; Murphy and Alexopoulos, 2006). Early identification of inhibition impairments would not only facilitate recognition of individuals at risk of suicide but also help the clinician to adjust medication and treatment in general (Alexopoulos et al., 2009).

The case-control design represents a limitation of our study and precludes strong causal inferences. Another limitation is the small sample size. Moreover, it would have been interesting to perform neuropsychological assessment at the same time of the day for all participants, which was not possible. Finally, all patients were medicated but antidepressants were started very shortly before the neuropsychological assessment making it unlikely to strongly influence the results. In addition, non-suicidal patients who received benzodiazepines more frequently had better performance.

\section{Conclusion}

In order to determine suitable policy and strategies for preventative interventions, it is important to identify risk factors associated with late-life suicide (Alexopoulos et al., 2009). Results from this study may shed light on specific interventions targeting cognitive impairment in the prevention of late-life suicide, as it is proposed for late-life depression.

\section{Role of funding source}

None.

\section{Conflict of interest}

All authors have no conflicts of interest.

None of the authors has any competing financial interests for this manuscript.

- S. Richard-Devantoy: no competing financial interests exist.

- F. Jollant: no competing financial interests exist.

- Z. Kefi: no competing financial interests exist.

- G. Turecki: no competing financial interests exist.

- JP. Olié: no competing financial interests exist.

- C. Annweiler: no competing financial interests exist.

- O. Beauchet: no competing financial interests exist.

- D. Le Gall: no competing financial interests exist.

\section{Acknowledgment}

None.

\section{References}

Alexopoulos, G.S., Bruce, M.L., Hull, J., Sirey, J.A., Kakuma, T., 1999. Clinical determinants of suicidal ideation and behavior in geriatric depression. Archives of General Psychiatry 56, 1048-1053.

Alexopoulos, G.S., Katz, I.R., Bruce, M.L., Heo, M., Ten Have, T., Raue, P., Bogner, H.R., Schulberg, H.C., Mulsant, B.H., Reynolds, C.F.R., Prospect Group, 2005. Remission in depressed geriatric primary care patients: a report from the PROSPECT study. The American Journal of Psychiatry $162,718-724$.

Alexopoulos, G.S., Reynolds, C.F.R., Bruce, M.L., Katz, I.R., Raue, P.J., Mulsant, B.H., Oslin, D.W., Ten Have, T., PROSPECT Group, 2009. Reducing suicidal ideation and depression in older primary care patients: 24-month outcomes of the PROSPECT study. The American Journal of Psychiatry 166, $882-890$.

Burgess, P.W., Shallice, T., 1996. Bizarre responses, rules detection and frontal lobe lesions. Cortex 32, 241-259.

Butters, M.A., Whyte, E.M., Nebes, R.D., Begley, A.E., Dew, M.A., Mulsant, B.H., Zmuda, M.D., Bhalla, R., Meltzer, C.C., Pollock, B.G., Reynolds, C.F.R., Becker, J.T., 2004. The nature and determinants of neuropsychological functioning in late-life depression. Archives of General Psychiatry 61, 587-595.

Connelly, S.L., Hasher, L., Zacks, R.T., 1991. Age and reading: the impact of distraction. Psychology and Aging 6, 533-541.

Conwell, Y., Cailting, T., 2008. Suicidal behaviors in elders. The Psychiatric Clinics of North America 31, 333-356.

Diekstra, R.F., Gulbinat, W., 1993. The epidemiology of suicidal behaviour: a review of three continents. World Health Statistics Quarterly 46, 52-68.

Dombrovski, A.Y., Butters, M.A., Reynolds III, C.F., Houck, P.R., Clark, L., Mazumdar, S., Szanto, K., 2008. Cognitive performance in suicidal depressed elderly: preliminary report. The American Journal of Geriatric Psychiatry 16, 109-115.

Dombrovski, A.Y., Clark, L., Siegle, G.J., Butters, M.A., Ichikawa, N., Sahakian, B.J., Szanto, K., 2010. Reward/punishment reversal learning in older suicide attempters. The American Journal of Psychiatry 167, 699-707.

Dombrovski, A.Y., Szanto, K., Siegle, G.J., Wallace, M.L., Forman, S.D., Sahakian, B., Reynolds III, C.F., Clark, L., 2011. Lethal forethought: delayed reward discounting differentiates high- and low-lethality suicide attempts in old age. Biological Psychiatry 70, 138-144.

Elderkin-Thompson, V., Mintz, J., Haroon, E., Lavretsky, H., Kumar, A., 2007. Executive dysfunction and memory in older patients with major and minor depression. Archives of Clinical Neuropsychology 22, 261-270.

Folstein, M.E., Folstein, S.E., Mchugh, P.R., 1975. Mini-mental state. A pratical method for grading th cognitive state of patients for the clinician. Journal of Psychiatric Research 12, 189-198. 
Fossati, P., 2006. Plasticité neuronale sous-corticale: impact thérapeutique potentiel dans la dépression. Encephale 32, S40-S43.

Godefroy, O., Jeannerod, M., Allain, P., Le Gall, D., 2008. Frontal lobe, executive functions and cognitive control. Revue Neurologique 164 (Suppl. 3), S119-S127.

Harriss, L., Hawton, K., 2005. Suicidal intent in deliberate self-harm and the risk of suicide: the predictive power of the Suicide Intent Scale. Journal of Affective Disorders 86, 225-233.

Hasher, L., Zacks, R.T., Cynthia, P.M., 1999. Inhibitory control, circadian arousal, and age. In: Gopher, D., Koriat, A. (Eds.), Attention and Performance XVII. MIT Press, Cambridge.

Hasselbalch, B.J., Knorr, U., Kessing, L.V., 2011. Cognitive impairment in the remitted state of unipolar depressive disorder: a systematic review. Journal of Affective Disorders 134, 20-31.

Hawton, K., Van Heeringen, K., 2009. Suicide. Lancet 373, 1372-1381.

Herrmann, L.L., Goodwin, G.M., Ebmeier, K.P., 2007. The cognitive neuropsychology of depression in the elderly. Psychological Medicine 37, 1693-1702.

Jollant, F., Bellivier, F., Leboyer, M., Astruc, B., Torres, S., Verdier, R., Castelnau, D., Malafosse, A., Courtet, P., 2005. Impaired decision making in suicide attempters. The American Journal of Psychiatry 162, 304-310.

Jollant, F., Lawrence, N.L., Olie, E., Guillaume, S., Courtet, P., 2011. The suicidal mind and brain: a review of neuropsychological and neuroimaging studies. The World Journal of Biological Psychiatry 12, 319-339.

Joormann, J., Gotlib, I.H., 2008. Updating the contents of working memory in depression: interference from irrelevant negative material. Journal of Abnormal Psychology 117, 182-192.

Joormann, J., Siemer, M., Gotlib, I.H., 2007. Mood regulation in depression: differential effects of distraction and recall of happy memories on sad mood. Journal of Abnormal Psychology 116, 484-490.

Kane, M.J., Engle, R.W., 2002. The role of prefrontal cortex in workingmemory capacity, executive attention, and general fluid intelligence: an individual-differences perspective. Psychonomic Bulletin Review 9, 637-671.

Keilp, J.G., Sackeim, H.A., Brodsky, B.S., Oquendo, M.A., Malone, K.M., Mann, J.J., 2001. Neuropsychological dysfunction in depressed suicide attempters. The American Journal of Psychiatry 158, 735-741.

Keilp, J.G., Gorlyn, M., Oquendo, M.A., Burke, A.K., Mann, J.J., 2008. Attention deficit in depressed suicide attempters. Psychiatry Research 159, 7-17.

King, D.A., Conwell, Y., Cox, C., Henderson, R.E., Denning, D.G., Caine, E.D., 2000. A neuropsychological comparison of depressed suicide attempters and nonattempters. The Journal of Neuropsychiatry and Clinical Neurosciences $12,64-70$

Kramer, A.F., Humphrey, D.G., Larish, J.F., Logan, G.D., Strayer, D.L., 1994. Aging and inhibition: beyond a unitary view of inhibitory processing in attention. Psychology and Aging 9, 491-512.

Lecrubier, Y., Sheehan, D.V., Weiller, E., Amorim, P., Bonora, I., Harnett Sheehan, K., Janavs, J., Dunbar, G.C., 1997. The Mini International Neuropsychiatry Interview (MINI). A short diagnostic structured interview: reliability and validity according to the CIDI. European Psychiatry 12, 224-231.
Malloy-Diniz, L.F., Neves, F.S., Abrantes, S.S., Fuentes, D., Correa, H., 2009. Suicide behavior and neuropsychological assessment of type I bipolar patients. Journal of Affective Disorders 112, 231-236.

Marzuk, P.M., Hartwell, N., Leon, A.C., Portera, L., 2005. Executive functioning in depressed patients with suicidal ideation. Acta Psychiatrica Scandinavica 112, 294-301.

Mcdowd, J.M., Oseas-Kreger, D.M., Filion, D.L., 1995. Inhibitory processes in cognition and aging. In: Dempster, F.N., Brainerd, C.J. (Eds.), Interference and Inhibition in Cognition. Academic Press, San diego.

Mcgirr, A., Dombrovski, A.Y., Butters, M.A., Clark, L., Szanto, K., 2012. Deterministic learning and attempted suicide among older depressed individuals: Cognitive assessment using the Wisconsin Card Sorting Task. Journal of Psychiatric Research 46 (2), 226-232.

Mclennan, S.N., Mathias, J.L., 2010. The depression-executive dysfunction (DED) syndrome and response to antidepressants: a meta-analytic review. International Journal of Geriatric Psychiatry 25, 933-944.

Miyake, A., Friedman, N.P., Emerson, M.J., Witzki, A.H., Howerter, A., Wager, T.D., 2000. The unity and diversity of executive functions and their contributions to complex "Frontal Lobe" tasks: a latent variable analysis. Cognitive Psychology 41, 49-100.

Morrison, R., O'Connor, R.C., 2008. A systematic review of the relationship between rumination and suicidality. Suicide \& Life-Threatening Behavior 38, 523-538.

Murphy, C.F., Alexopoulos, G.S., 2006. Attention network dysfunction and treatment response of geriatric depression. Journal of Clinical and Experimental Neuropsychology 28, 96-100.

Raust, A., Slama, F., Mathieu, F., Roy, I., Chenu, A., Koncke, D., Fouques, D. Jollant, F., Jouvent, E., Courtet, P., Leboyer, M., Bellivier, F., 2007. Prefrontal cortex dysfunction in patients with suicidal behavior. Psychological Medicine 37, 411-419.

Seron, X., Van Der Linden, M., Andrès, P., 1999. Le lobe frontal: à la recherche des spécificités fonctionnelles. In: Van Der Linden, M., Seron, X., Le Gall, D., Andréas, P. (Eds.), Neuropsychologie des lobes frontaux. Solal, Marseille.

Shallice, T., Burgess, P.W., 1991. Deficits in strategy application following frontal lobe damage in man. Brain 114, 727-741.

Szanto, K., Holly, G., Reynolds Iii, C., 2001. Suicide in the elderly. Clinical Neuroscience Research 1, 366-376.

Turner, G.R., Spreng, R.N., 2012. Executive functions and neurocognitive aging: dissociable patterns of brain activity. Neurobiology of Aging 33 (4), 826.e1-826.e13.

Van Heeringen, C., Bijttebier, S., Godfrin, K., 2011. Suicidal brains: a review of functional and structural brain studies in association with suicidal behaviour. Neuroscience and Biobehavioral Reviews 35, 688-698.

Wang, M., Gamo, N.J., Yang, Y., Jin, L.E., Wang, X.J., Laubach, M., Mazer, J.A., Lee, D., Arnsten, A.F., 2011. Neuronal basis of age-related working memory decline. Nature 476, 210-213.

Zacks, R.T., Hasher, L., Radvansky, G., 1999. Studies of directed forgetting in older adults. Journal of Experimental Psychology: Learning, Memory, and Cognition 22, 143-156. 